NBER WORKING PAPER SERIES

\title{
INTEREST RATES AND INITIAL PUBLIC OFFERINGS
}

\author{
Boyan Jovanovic \\ Peter L. Rousseau \\ Working Paper 10298 \\ http://www.nber.org/papers/w10298 \\ NATIONAL BUREAU OF ECONOMIC RESEARCH \\ 1050 Massachusetts Avenue \\ Cambridge, MA 02138 \\ February 2004
}

The views expressed herein are those of the authors and not necessarily those of the National Bureau of Economic Research.

(C2004 by Boyan Jovanovic and Peter L. Rousseau. All rights reserved. Short sections of text, not to exceed two paragraphs, may be quoted without explicit permission provided that full credit, including $\odot$ notice, is given to the source. 
Interest Rates and Initial Public Offerings

Boyan Jovanovic and Peter L. Rousseau

NBER Working Paper No. 10298

February 2004

JEL No. E4, G3, N1

\section{ABSTRACT}

We study the relation between IPO investment and the rate of interest. We model the IPO timing decision and show that the implied relation between interest rates and investment is non-monotonic, and the data support the implication. At low rates of interest firms delay their IPOs. This happens because during the pre-IPO period the firm forgoes earnings that do not matter as much at low interest rates. The 1950's and early 1960's, especially, were periods of very low real interest rates, and IPO investment was low, with firms delaying their IPOs significantly. A qualitative difference seems to exist between investment of IPO-ing firms and the investment of incumbent firms which is decreasing in the interest rate, as neoclassical theory predicts.

Boyan Jovanovic Department of Economics New York University and University of Chicago 1126 E. $59^{\text {th }}$ Street Chicago, IL 60637 and NBER

bjovanov@uchicago.edu

Peter L. Rousseau Department of Economics Vanderbilt University and University of Michigan

611 Tappan Street Ann Arbor, MI 48109 and NBER roussep1@umich.edu 


\title{
Interest Rates and Initial Public Offerings
}

\author{
Boyan Jovanovic and Peter L. Rousseau*
}

February 2, 2004

\begin{abstract}
We study the relation between IPO investment and the rate of interest. We model the IPO timing decision and show that the implied relation between interest rates and investment is non-monotonic, and the data support the implication. At low rates of interest firms delay their IPOs. This happens because during the pre-IPO period the firm forgoes earnings that do not matter as much at low interest rates. The 1950's and early 1960's, especially, were periods of very low real interest rates, and IPO investment was low, with firms delaying their IPOs significantly. A qualitative difference seems to exist between investment of IPO-ing firms and the investment of incumbent firms which is decreasing in the interest rate, as neoclassical theory predicts.
\end{abstract}

\section{Introduction}

A firm's initial public offering on the stock market - its "IPO" - represents a transfer of ownership of the firm and its assets into the hands of the public, at least in part. At the same time an IPO also augments the funds available to the firm, thereby enabling it to invest more. Clementi (2003), Pastor and Veronesi (2003) and Jovanovic and Rousseau (2001) focus on the investment motive behind IPOs. The present paper also treats a firm's IPO as inseparable from a simultaneous physical investment.

The paper finds that IPOs are qualitatively different from other investments, especially investments made by stock-market incumbents. It investigates, further, the role that the rate of interest plays in influencing IPOs. It finds that the relation between the two is non-monotonic. Very high rates of interest discourage investment for the usual reason, namely that when future income is discounted more heavily, it is not worthwhile to sacrifice current resources. Very low rates of interest, however,

*Boyan Jovanovic is professor of economics at the University of Chicago and New York University, a research associate of the National Bureau of Economic Research (NBER), and a consultant to the Federal Reserve Bank of Chicago. Peter L. Rousseau is associate professor of economics at Vanderbilt University and a research associate of the NBER. The authors thank the NSF for financial help. 


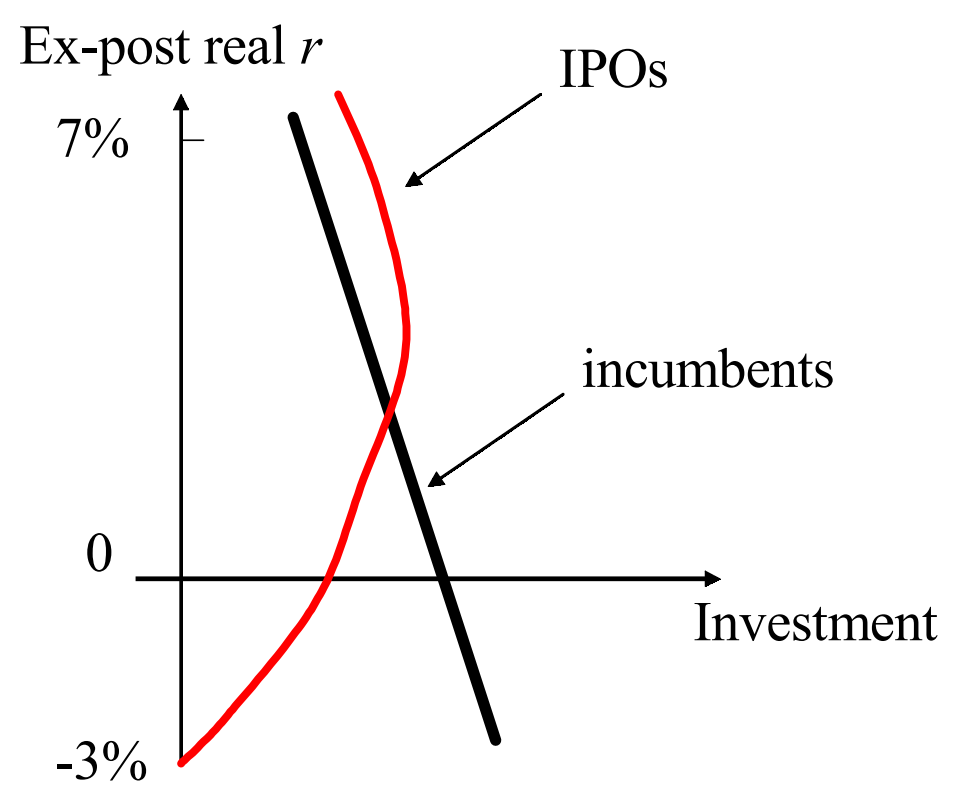

Figure 1: Two Qualitatively Different investment SChedules.

also discourage investment if that investment is irreversible. This is because when interest rates are low, it is not as costly to wait for conditions under which the investment is more favorable. Similar results are in Chetty (2003) and Jovanovic and Rousseau (2001) who also provide an information-theoretic rationale for the gains to waiting, but these authors do not test for non-monotonicity. A rough summary of the estimated contrast between the two forms of investment - IPOs vs. established firms - is in Figure 1. Aggregate investment is negatively though not strongly related to interest rates. IPO investment, on the other hand, has a backward bending portion, with the positively-sloped portion much more pronounced. The two curves are not properly scaled on the horizontal axis, though, because IPO investment is a small fraction of all investment - roughly 11 percent over the past 40 years.

The non-monotonicity of IPO-ing firms' physical investment in the interest rate stems, ultimately, from the fact that the firm is giving up profits while it waits to IPO. Waiting itself delivers information, i.e., human capital, hence what really goes on is a substitution of one form of capital for another. An IPO-ing firm faces more uncertainty than incumbent firms, and it has a greater incentive to wait and gather information before it invests. We comment on this again in the conclusion, and on the implications that it may have for countries like Japan that are experiencing low investment in spite of enjoying very low interest rates.

The plan of the paper is as follows: Section 2 explains the model, and Section 3 describes its main implications for the data that we have. Section 4 tests those implications, and Section 5 discusses some related literature. Section 6 concludes. 


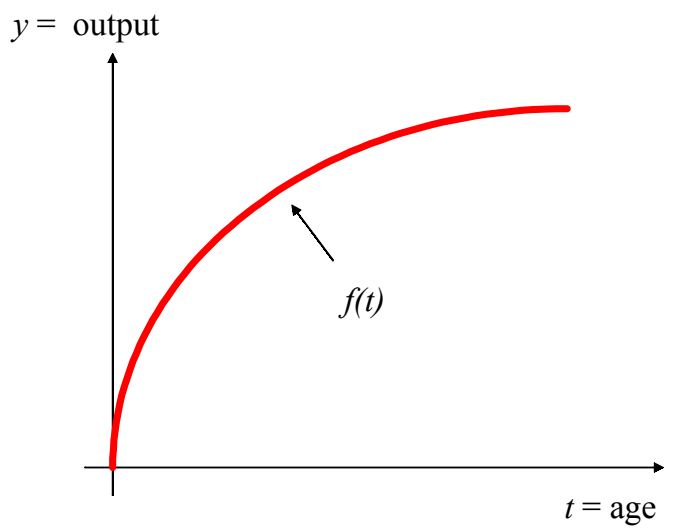

Figure 2: Post-IPO output of the firm as a function of its age at IPO.

\section{The model: IPO as an investment}

The following model is a simplified version of Jovanovic and Rousseau (2001). Suppose the firm lives forever, and has the property rights to a project. It produces output using knowledge, $h$, and physical capital $k$. The firm starts to receive net revenue cash only after its IPO. Let $T$ denote the waiting time until IPO. Suppose that while it waits, the firm's potential output is

$$
y=f(T) .
$$

We assume that $f$ increases with $T$ but at a diminishing rate, as drawn in Figure 2. In this formulation the firm starts receiving $y$ only after implementing the project (which is often untrue - e.g., Goldman Sachs, McDonalds, etc.). At that point the project stops improving (i.e., there is no learning by doing. This is a learning or doing model). Moreover there are no direct costs. It makes sense if

1. funds are a constraint for private companies,

2. IPOs can deliver the funds for a significant expansion, and

3. upon the initial expansion, the firm is irrevocably defined and "fossilized" as in the "putty clay" vision of investment.

In that case the IPO decision is much like the decision of how long to remain in school. This is like perfecting an idea before taking out a patent on it. 


\subsection{Choosing the IPO date when there is no physical capital}

If the firm lives forever and has the property rights to its project, it must just decide when to implement it. There are no direct costs. Only implicit "foregone-earnings" costs. Therefore its problem is like that of optimally cutting down a tree; the firm maximizes the present value of its future net revenues:

$$
\max _{T} e^{-r T} \frac{1}{r} f(T) .
$$

After rearrangement, the FOC is

$$
f(T)=\frac{1}{r} f^{\prime}(T) .
$$

Second-order conditions hold if $f$ is concave. The LHS of (1) is the foregone-earnings costs of waiting another period. In the problem as stated, this is the only cost. The RHS is the gain from waiting. Since this gain is received in every subsequent (production) period, it is capitalized, and hence the $r$ in the denominator. It is more revealing to write the condition as

$$
g=r
$$

where

$$
g \equiv \frac{f^{\prime}(T)}{f(T)}
$$

is the rate of growth of potential output. Thus the IPO occurs when $g$ equals the rate of interest.

Example.-As an example, consider $f(t)=A t^{\alpha}$ where $\alpha<1$. Here the condition reads $\frac{\alpha}{T}=r$ so that

$$
T=\frac{\alpha}{r} .
$$

In this simple version of the model, then, a rise in the rate of interest hastens the IPO because it makes the foregone earning cost of waiting more important relative to the future gains from waiting. Interestingly, the productivity of the firm, $A$, does not affect the firm's IPO date because it simply scales both costs and revenues in the same proportion.

The parameter $\alpha$ will be important in what follows. It measures the gain in productivity that the firm gets by delaying its IPO. Delay lets the firm resolve technological uncertainties, perfect its ideas, and choose the right inputs for its production process. As Chetty (2003) emphasizes, such a delay makes sense if the investment is to some extent irreversible, and this is probably true for most IPOs - at the IPO stage a prospectus is drafted and the funds raised at IPO are used to implement the ideas that the prospectus contains. These are some reasons why $\alpha$ is positive. The more relevant these considerations are to a sector or to an epoch in history, the larger should $\alpha$ be for that sector or that epoch. 


\subsection{Adding physical capital}

To the extent that IPOs entail spending on capital goods (as suggested by the evidence in Jain and Kini (1994) that we cited above), this implies that the effect of the real rate of interest on investment is unambiguously positive! Lower rates discourage IPO investments by inducing firms to wait longer so as to perfect their investments. Information-theoretic bases for this conclusion are in Chetty (2003) and Jovanovic and Rousseau (2001). But they allow for capital spending at $T$, so let us now introduce a capital expenditure of $I$ that is incurred at the IPO date. ${ }^{1}$ This modifies the firm's problem as follows:

$$
\max _{T} e^{-r T}\left\{-I+\frac{1}{r} f(T)\right\} .
$$

Now the first-order conditions read

$$
r I-f(T)+\frac{1}{r} f^{\prime}(T)=0,
$$

so that instead of (2), the condition of optimality reads

$$
g=r-\left(\frac{I}{f(T)}\right) r^{2} .
$$

Now $g$ is essentially a quadratic in $r$. When $r$ is small, the effect of $r$ on $g$ is positive as before, but when $r$ gets large, the opposite it true, and the effect of $r$ on $g$ is non-monotonic. Note, too, that the coefficient on $r^{2}$ is the capital-output ratio. As a result, the effect on $T$ is non-monotonic too, and with it the effect on IPO investment.

The example again.-To illustrate this, let us return to, and augment the example $f(t)=A t^{\alpha}$ that we studied above. The first-order condition now reads

$$
-A t^{\alpha}+r I+\frac{\alpha A}{r} t^{\alpha-1}=0
$$

The value of $T$ that satisfies this equation is the firm's IPO date. Equation (6) implicitly defines $T$ as a function of the various parameters and, in particular, as a function of $r$. Sometimes it admits an explicit solution. Let us take $\alpha=1 / 2$, for which we can solve explicitly for $T:^{2} t-\left(\frac{r I}{A}\right) t^{1-\alpha}-\frac{\alpha}{r}=0$

$$
T=\frac{1}{4}\left(\left(\frac{r I}{A}\right)+\sqrt{\left(\frac{r I}{A}\right)^{2}+\frac{2}{r}}\right)^{2} .
$$

\footnotetext{
${ }^{1}$ Some of the costs incurred at IPO are transactions costs - see Lee et al. (1996). We shall lump all costs into $I$ and treat them as "investment."

${ }^{2}$ The quadratic equation in $t^{1 / 2}$ that $T$ solves is

$$
t-\left(\frac{r I}{A}\right) t^{1 / 2}-\frac{1}{2 r}=0 .
$$
}




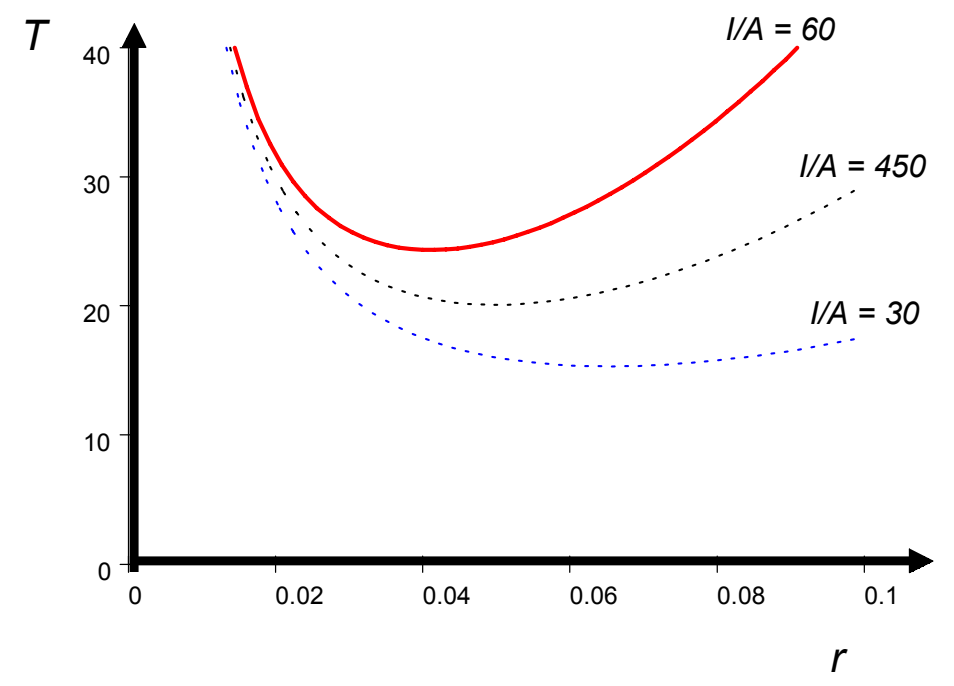

Figure 3: Plot of $T$ ON $r$ IN (7) When $\alpha=1 / 2$.

Note that when $I=0$, this collapses to the expression in (3) evaluated at $\alpha=1 / 2$.

From (7) we see that for small $r$, the term $2 / r$ dominates, driving $T$ to infinity. For large $r$, the term $r I / A$ dominates, again driving $T$ to infinity. We therefore have a U-shaped relation between $r$ on the horizontal axis and $T$ on the vertical. We illustrate this in Figure 3 for the case where $I=30 A$. We also plot $T$ for the case where $I=45 \mathrm{~A}$, and $I=60 \mathrm{~A}$. We note that $(i)$ the curves bottom out at levels of $r$ ranging between 5 and 10 percent, and $(i i)$ higher investment outlays imply longer waiting at all levels of interest. For practical purposes, however, the size of the outlay, $I$, starts to matter only when the interest rate is relatively high, say above 4 percent.

\section{Implications of the model}

The model has time-series and cross-section implications. The time-series implications concern low-frequency movements in $T$ and the market value of the firm at IPO, which we denote as $v$. We are especially interested in the relation between interest rates and IPO investment. The model assumes that $r$ is fixed, and therefore we may, at best, take Figure 3 to predict the effects on $T$ of low-frequency movements in $r$. These movements will induce changes in spending $I$ that we shall associate with IPO investment.

1. $T$ vs. $r$.-At low frequencies, the relation between $T$ and $r$ is U-shaped, as Figure 3 shows. This means that the investment schedule is backward bending. 


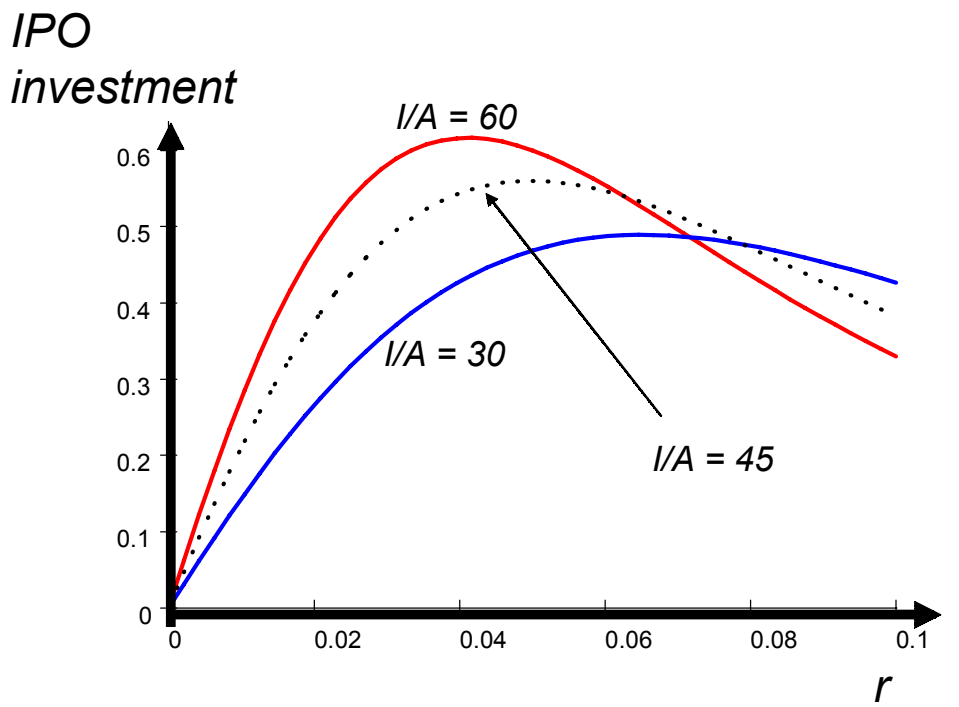

Figure 4: BaCkWARd Bending investment SChedules in (7) When $\alpha=1 / 2$.

2. IPO Investment vs. $r .-\mathrm{A}$ rise in $T$ means that investment $I$ is postponed. Interest-rate variation at low frequencies will produce changes in investment that change in the direction opposite to the change in $T$. Therefore the relation between IPO investment on the vertical axis and the rate of interest on the horizontal should have an inverted-U shape. We illustrate this in Figure 4. The reason why the curves cross is that the investment associated with a particular $I$ is weighted by $1 / T$ and yet $T$ is increasing in $I$, and the ratios are not ordered the same way at different levels of $r$. But what is important here is the inverted$\mathrm{U}$ shape in the graph and this is what we shall look for in the data.

3. T vs. the capital-output ratio. From (5), the capital-output ratio is $\frac{I}{f(T)}=\frac{1}{r}-\frac{g}{r^{2}}$. In the example, the capital-output ratio is

$$
\frac{I}{f(T)}=\frac{1}{r}-\frac{\alpha}{r^{2} T}
$$

This means that when the capital-output ratio is higher for reasons other than variation in $r$ or $\alpha$, we should expect that $T$ also be higher. On the other hand, if the overriding source of variation is changes in $\alpha$, we may see no relationship between $T$ and the capital-output ratio. To see why this is so, let us use (3) as an approximation, which tells us that as $\alpha$ varies, $T$ will be roughly proportional to $\alpha$. Then in (8) variation in $T$ will be offset by equi-proportional changes in $\alpha$ that will fully offset any direct effect that $T$ would have on $v$.

4. T vs. IPO size.-The nature of this relation depends on whether firms differ mainly with respect to their capital requirements, $I$, or mainly with respect to 
their pre-IPO growth opportunities, $\alpha$. From (4) we get that

$$
v=\frac{1}{r^{2}} f^{\prime}(T)=\frac{\alpha}{r^{2}} T^{\alpha-1} .
$$

Variation in $\alpha$ produces a positive relation between the two: Once again, using (3) as an approximation, we expect that $T$ will be roughly proportional to $\alpha$. Substituting $\alpha \approx r T$ into the right-hand side of (9), we obtain

$$
v \approx \frac{1}{r} T^{\alpha}
$$

Thus, when the overriding source of variation in the data is changes in pre-IPO growth opportunities, we should expect an iso-elastic, positive relation between IPO size, $v$, and IPO-ing firm age, $T$. On the other hand, variation in $I$ produces a negative relation between $T$ and $I$ so that (9) also implies that

$$
T=\left(\frac{\alpha}{r^{2} v}\right)^{1 /(1-\alpha)}
$$

Therefore changes in $v$ that do not originate in either $r$ or in $\alpha$ should cause $T$ to fall.

5. IPO size vs. r.-Let

$$
v \equiv \frac{1}{r} f(T)-I
$$

denote the market value of the firm at its IPO. When interest rates are moderate or low, say below 4 or 5 percent, a rise in interest rates unambiguously lowers $v$, both directly, and also by reducing $T$. At higher levels of $r$ the relationship is ambiguous. In spite of this ambiguity, we shall document the relation between $r$ and IPO size in the next section.

\section{Tests of the implications}

Having listed the main implications of the model, we report on how they fare with the data, taking them up in the order in which they are listed above.

\subsection{Testing $T$ vs. $r$}

The first implication says that the relation between $T$ and $r$ should be U-shaped. To measure $T$, we construct average waiting times from founding and incorporation to listing for exchange-listed firms since 1886 based on individual company histories and our extension of the stock files made available by the University of Chicago's Center for Research in Securities Prices (CRSP) database from its 1925 starting date back 


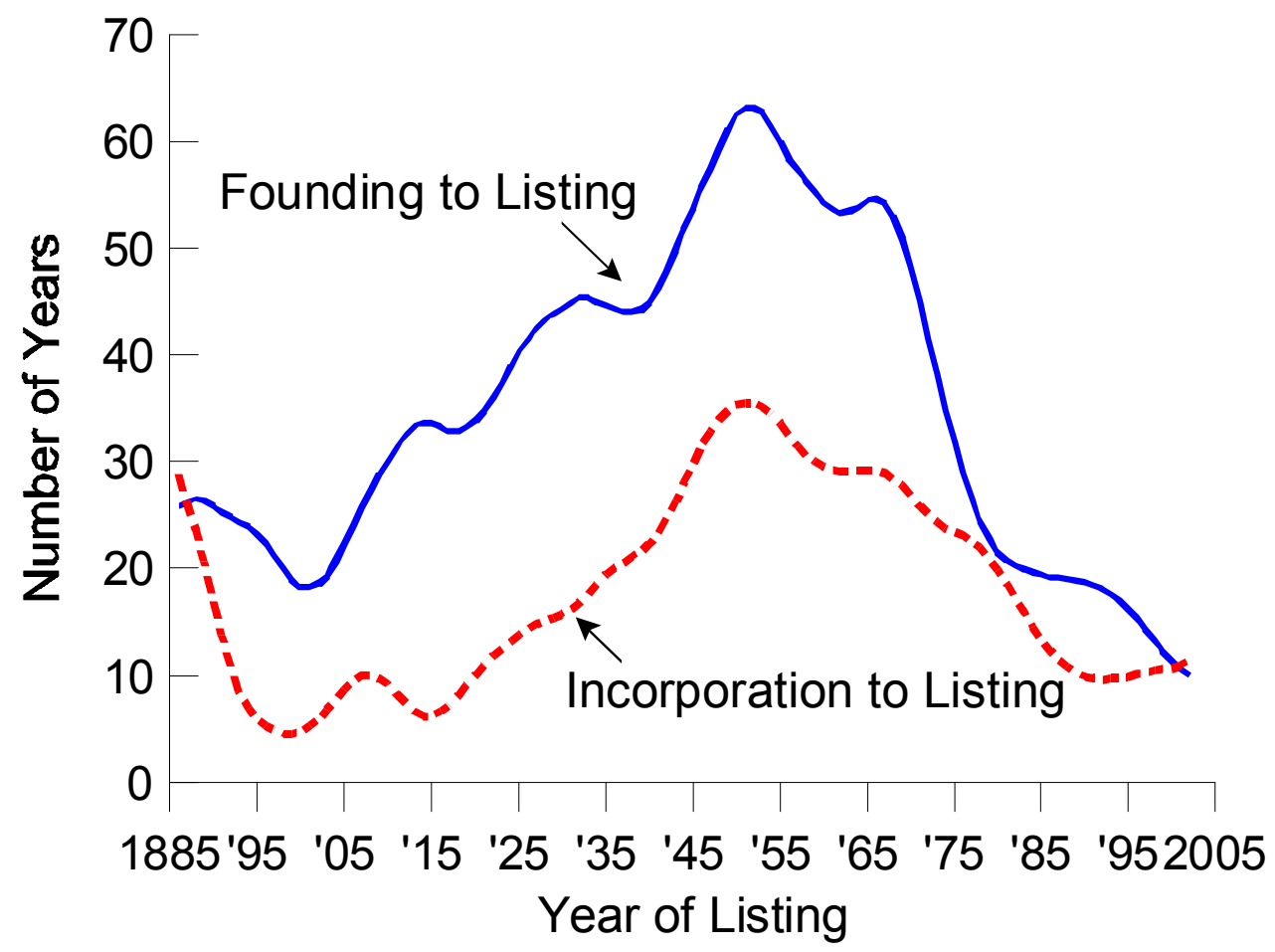

Figure 5: Waiting times to EXChange Listing, 1886-2002.

Table 1-Number of Firms in the Waiting-Time Sample

\begin{tabular}{ccrr}
\hline \hline & All New & $\begin{array}{c}\text { Included } \\
\text { Incorporations }\end{array}$ & $\begin{array}{c}\text { Included } \\
\text { Foundings }\end{array}$ \\
\hline 1890 's & 112 & 52 & 41 \\
CRSP Listings & 78 & 44 \\
1900 's & 112 & 190 & 97 \\
1920 's & 214 & 492 & 273 \\
1930 's & 545 & 197 & 78 \\
1940 's & 231 & 246 & 97 \\
1950 's & 271 & 241 & 78 \\
1960 's & 2,008 & 964 & 198 \\
1970 's & 4,517 & 1,405 & 262 \\
1980 's & 6,322 & 904 & 790 \\
1990 's & 7,850 & 1,539 & 1,939 \\
2000 s & 1,311 & 324 & 324 \\
\hline Totals & 23,747 & 6,632 & 4,221 \\
\hline
\end{tabular}




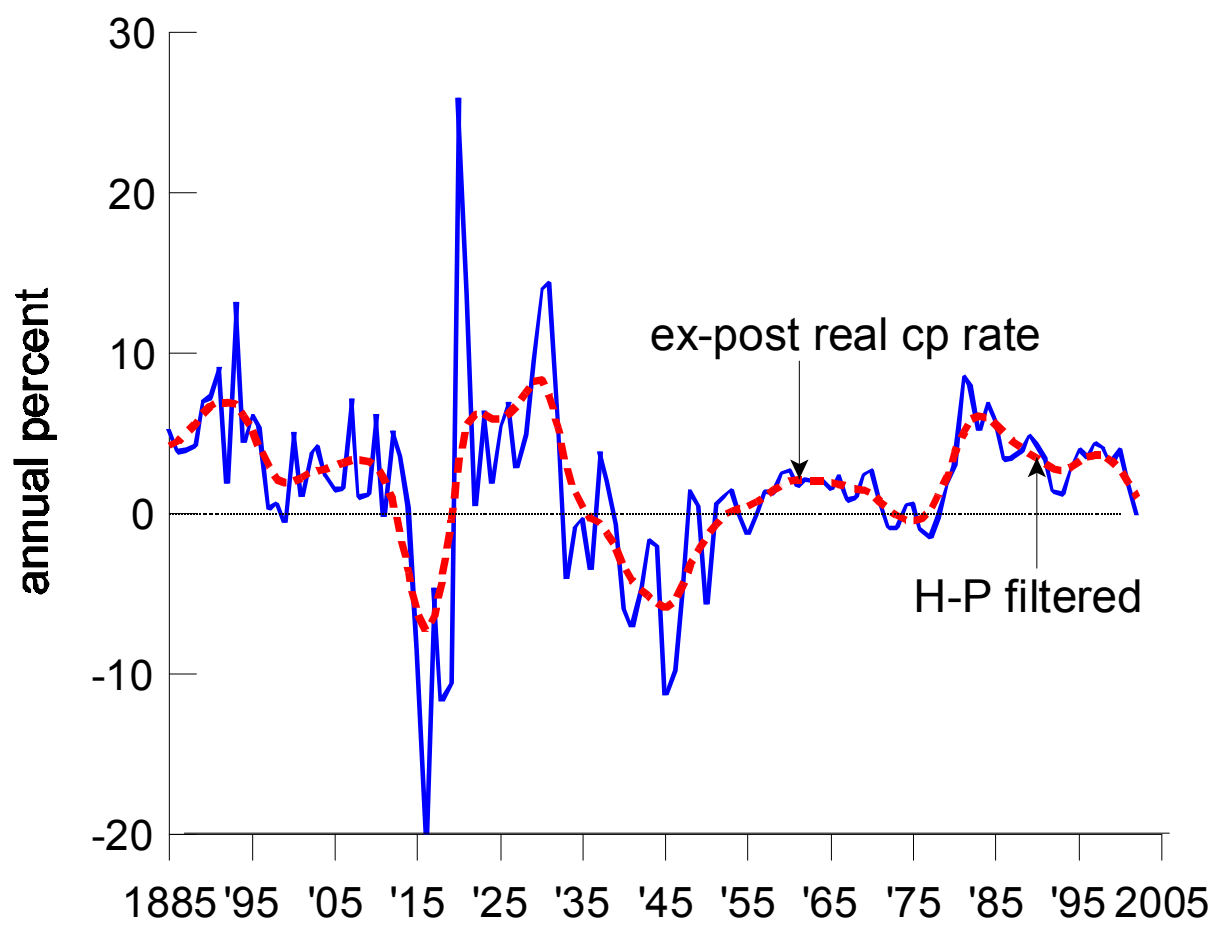

Figure 6: The EX-Post ReAl INTEREST RATE ON COMMERCIAL PAPER, 18852002.

through 1885 using newspaper sources. ${ }^{3}$ Figure 5 shows these series after smoothing with the Hodrick-Prescott filter. Table 1 shows the coverage of our collection of IPO waiting times by decade. Waiting times by either measure were longest in the 1950's and 1960's, and shortest at both ends of the 20th century.

Figure 6 shows the real interest rate on commercial paper with 30-90 days until maturity over the same time period, along with an HP-filtered trend. ${ }^{4}$ Real rates were lowest in the middle of the century, and the series is roughly U-shaped. The

\footnotetext{
${ }^{3}$ Listing years after 1925 are those for which firms enter CRSP. For 1885-1924, they are years in which prices first appear in the NYSE listings of The Annalist, Bradstreet's, The Commercial and Financial Chronicle, or The New York Times. The 6,632 incorporation dates used to construct Figure 5 are from Moody's Industrial Manual (1920, 1928, 1955, 1980), Standard and Poor's Stock Market Encyclopedia (1981, 1988, 2000), various editions of Standard and Poor's Stock Reports, and Mergent Online. The 4,221 foundings are from Dun and Bradstreet's Million Dollar Directory (2000), Moody's, Kelley (1954), and individual company websites. We linearly interpolate the series between missing points before applying the HP-filter to create the time series in the figure.

${ }^{4}$ Commercial paper rates are annual averages of 30-day terms from the FRED database (Federal Reserve Bank of St. Louis, 2003) for 1934-2002 and 60-90 day terms from Homer and Sylla (1991) for earlier years. We compute the ex-post return by subtracting inflation as computed by the growth of the implicit price deflator for GDP from the Bureau of Economic Analysis (2003) for 1929-2002 and Berry (1988) for earlier years.
} 


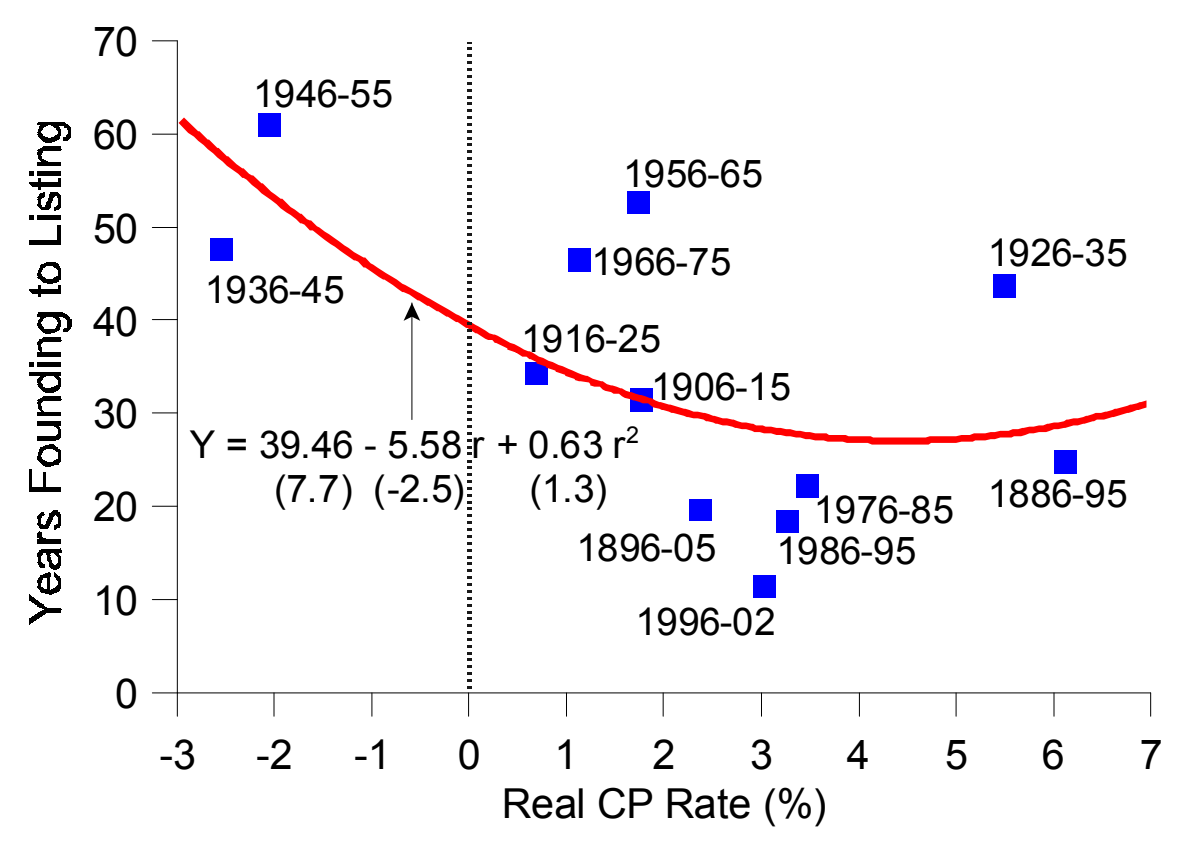

Figure 7: Scatterplot of $T$ (From Founding) ON $r$.

long wait times in the 1950's and the corresponding negative real interest rates appear to be roughly consistent with our model. To examine the low-frequency relationship between $T$ and $r$ more precisely, however, we average both across ten year periods and test for non-monotonicity in (7) with a quadratic regression

Figure 7 shows a scatterplot of decadal averages of $T$ on $r$, with $T$ measured as the number of years from founding to exchange listing. Figure 8 instead uses years from incorporation as the measure of $T$. In either case, a U-shaped pattern appears in the data. The regressions in Table 1 confirm this, with the coefficient on the real interest rate negative and significant at the 5 percent level for the linear term and positive for the quadratic term. We interpret this as supporting evidence for the first implication of our model. We note, however, that negative real interest rates are inconsistent with the model and that instead of varying between zero and ten percent (as it does in the theoretical plots of Figures 1-3), the decadal averages vary from about negative three percent to seven percent.

\subsection{Testing IPO and incumbents' investment vs. $r$}

The second implication deals with the relation between IPO investment and the real rate of interest. In testing for this, we offer a parallel analysis of the relation between aggregate investment (which is dominated by investment of stock-market incumbents) and interest rates. We do this because we wish to contrast the two relations. 


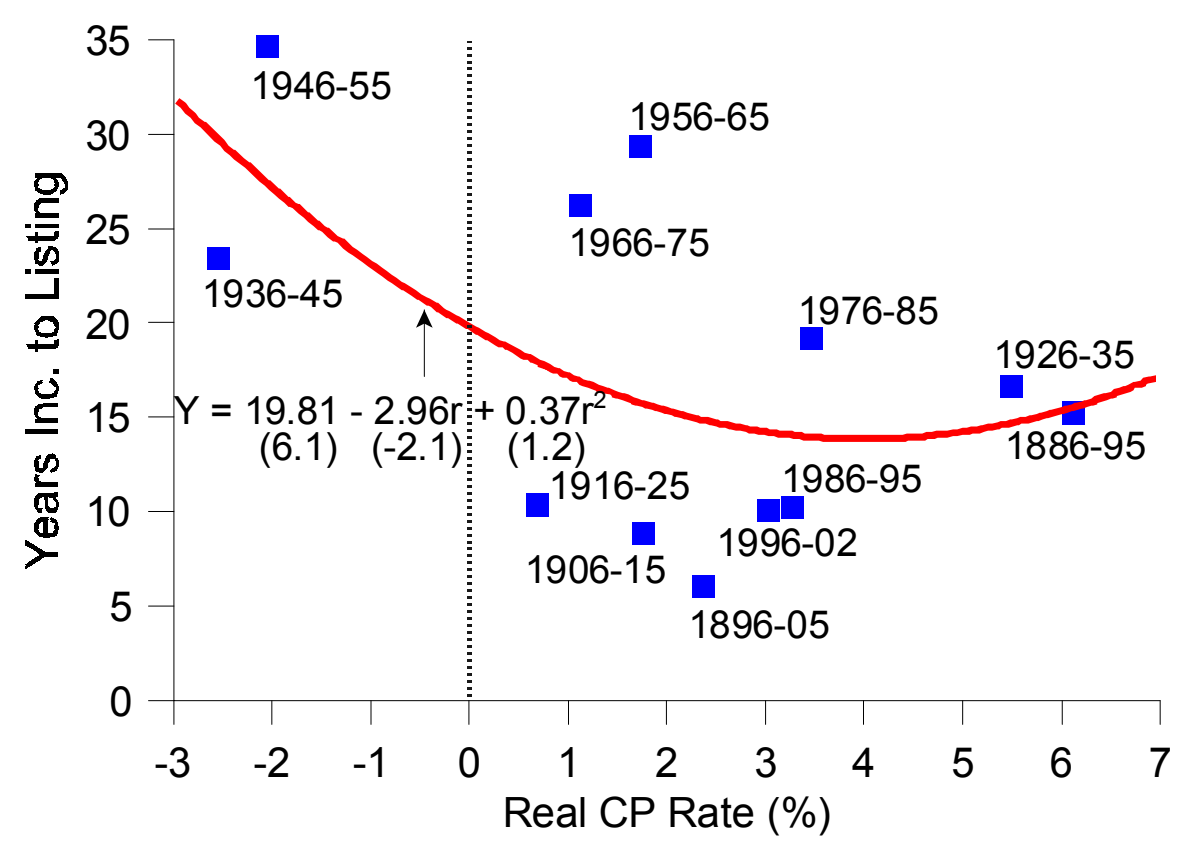

Figure 8: Scatterplot of $T$ (FROM incorporation) ON $r$.

Table 1. Regressions of waiting times $(T)$ on the real commercial paper rate $(r)$ by decade, 1886-2002.

\begin{tabular}{|c|c|c|c|c|}
\hline \multirow[b]{3}{*}{$r_{t}$} & \multicolumn{4}{|c|}{ Dependent variable } \\
\hline & \multicolumn{2}{|c|}{$T$ from founding } & \multicolumn{2}{|c|}{$T$ from incorporation } \\
\hline & $\begin{array}{c}-3.47 \\
(-2.23)\end{array}$ & $\begin{array}{l}-5.58 \\
(-2.46)\end{array}$ & $\begin{array}{c}-1.71 \\
(-1.77)\end{array}$ & $\begin{array}{l}-2.96 \\
(-2.07)\end{array}$ \\
\hline$r_{t}^{2}$ & & $\begin{array}{c}0.63 \\
(1.25)\end{array}$ & & $\begin{array}{c}0.37 \\
(1.17)\end{array}$ \\
\hline constant & $\begin{array}{l}41.68 \\
(8.37)\end{array}$ & $\begin{array}{l}39.46 \\
(7.65)\end{array}$ & $\begin{array}{l}21.11 \\
(6.80)\end{array}$ & $\begin{array}{l}19.81 \\
(6.10)\end{array}$ \\
\hline$R^{2}$ & .33 & .43 & .24 & .34 \\
\hline$N$ & 12 & 12 & 12 & 12 \\
\hline
\end{tabular}

Note: t-statistics are in parentheses. 


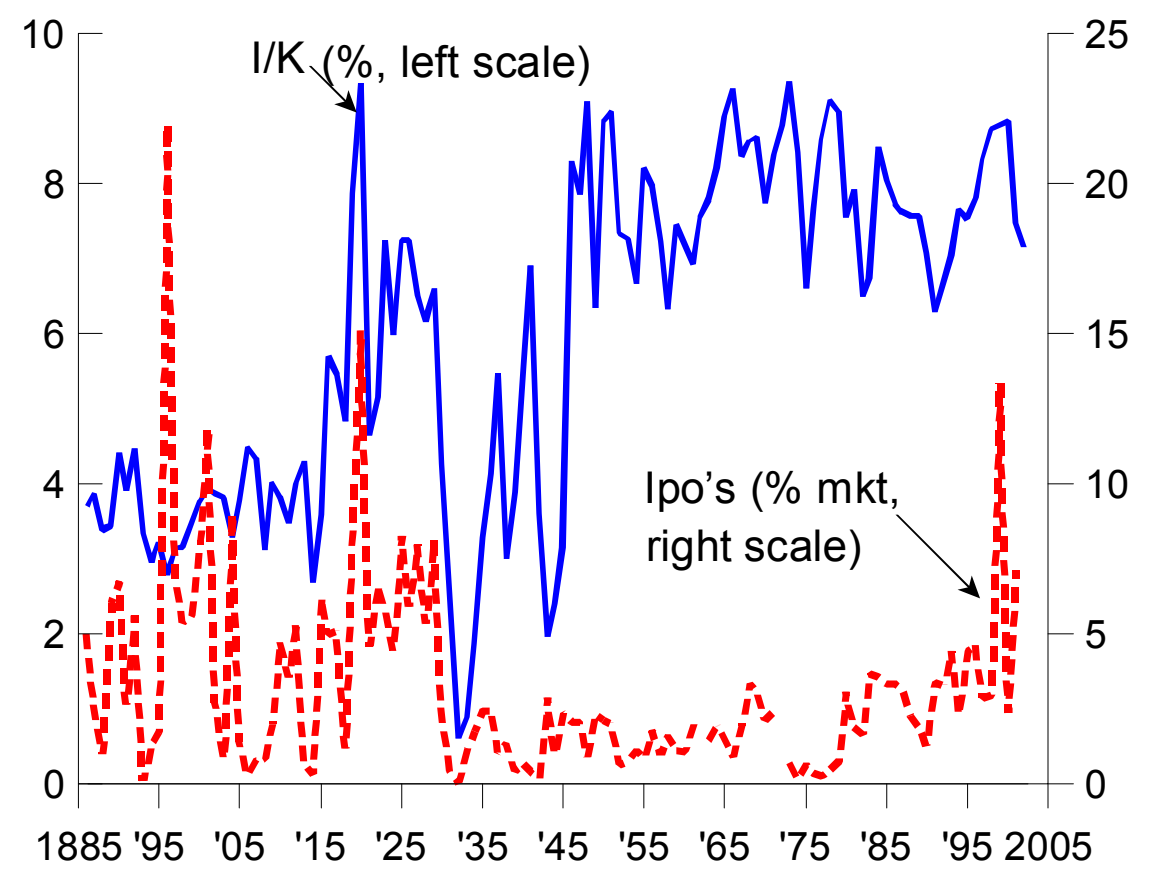

Figure 9: Annual IPOs as a Percent of Stock market value, and private INVESTMENT AS A PERCENT OF THE CAPITAL STOCK, 1886-2002.

IPO-ing firms probably face much greater uncertainty than do incumbent firms. IPO-ing firms are in the process of defining themselves, their products and their technologies, and once they have chosen these directions, there is no going back for most of them. Choosing the wrong standard, for example, can condemn a new business to an early demise. There is a real sense, then, in which their investments are irreversible.

Incumbent firms, on the other hand, firms that have chosen their domains of operation, face uncertainty more in the scale of demand, input prices, and so on, and therefore the risks that they face are of a different nature. There is less to be gained by waiting, less uncertainty to be resolved by delaying investment. Therefore we would expect incumbents to have investment related negatively to the rate of interest. So, while we shall not offer a model of incumbent investment, we note that the standard Q-theory model of investment - e.g., Hayashi (1982) - with convex adjustment costs and no irreversibilities, predicts that a rise in the interest rate reduces investment.

Our model implies that, unlike incumbent investment, the relation between IPO investment and the rate of interest should be an inverted-U. Figure 9 shows the two investment series that we consider. The solid line is private domestic investment as a percentage of the aggregate capital stock. ${ }^{5}$ The dashed line is the value of IPO-ing

\footnotetext{
${ }^{5}$ To build the investment rate series, we start with gross private domestic investment in current
} 


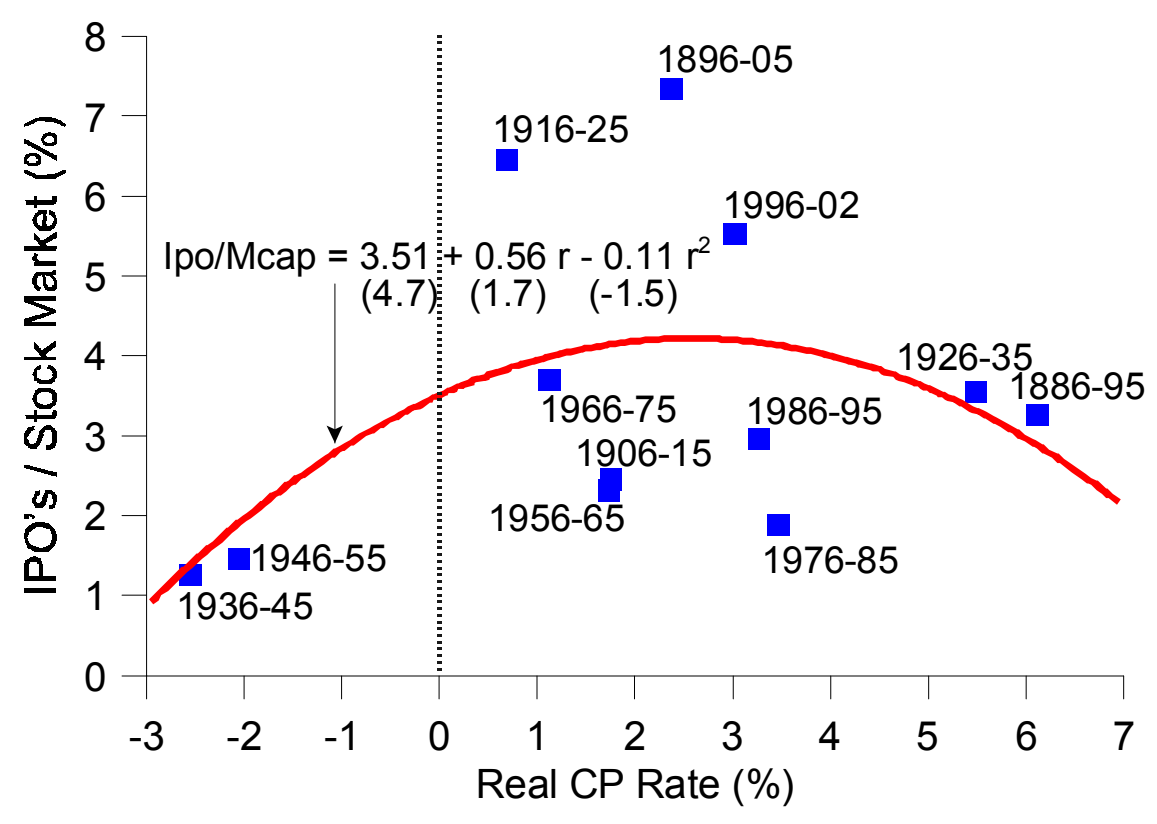

Figure 10: Scatterplot of IPOs as A Share of Stock Market CAPitalizaTION ON $r$.

firms at the end of each year as a percentage of total stock market capitalization. ${ }^{6}$ While investment rates tended to rise until the Great Depression and then stabilized after the Second World War, IPOs followed a more erratic pattern, with the value of new equity largest around the turn of the 20th century, around 1915, in the late 1920's, at the end of the Second World War, in the late 1960s, the mid-1980s, and the 1990s.

dollars from the Bureau of Economic Analysis (2003, Table 1, pp. 123-4) for 1929-2002 and join the gross capital formation series in current dollars, excluding military expenditures, from Kuznets (1961b, Tables T-8 and T-8a) for 1870-1929. We construct the net capital stock using the private fixed assets tables of the Bureau of Economic Analysis (2003) for 1925-2002. Then, using the estimates of the net stock of non-military capital from Kuznets (1961a, Table 3, pp. 64-5) in 1869, 1879, 1889, 1909, 1919, and 1929 as benchmarks, we use the percent changes in a synthetic series for the capital stock formed by starting with the 1869 Kuznets (1961a) estimate of $\$ 27$ billion and adding net capital formation in each year through 1929 from Kuznets (1961b) to create an annual series that runs through the benchmark points. Finally, we join the resulting series for 1870-1925 to the later BEA series. The investment rate that appears in Figure 9 is the ratio of our final investment series to the capital stock series, expressed as a percentage.

${ }^{6}$ The stock market data are from the CRSP files for 1925-2002. NYSE firms are available in CRSP continuously, AMEX firms after 1961, and NASDAQ firms after 1971. We extended the CRSP stock files backward from their 1925 starting year by collecting year-end observations from 1885 to 1925 for all common stocks traded on the NYSE. New listings are given by the total yearend market value of firms that entered our database in each year, excluding American Depository Receipts (ADR's). 


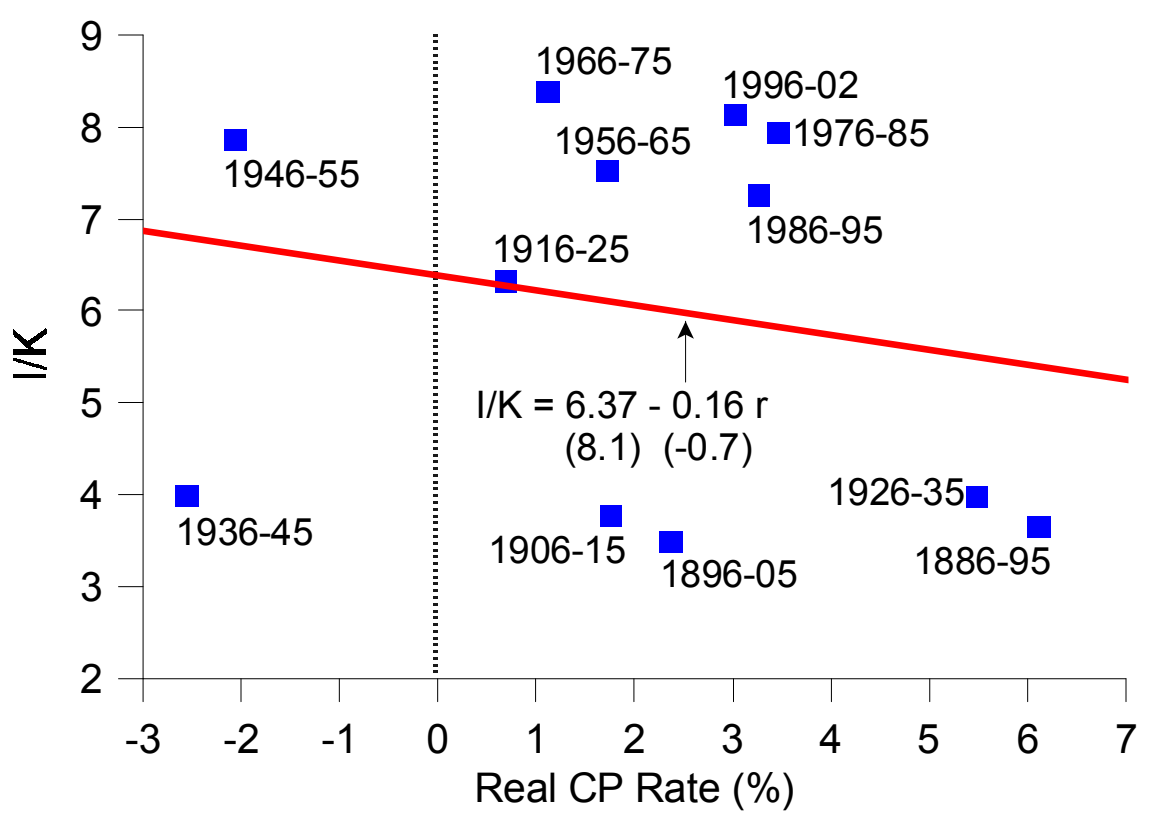

Figure 11: Scatterplot of the Investment RAte on $r$.

Table 2. Regressions of IPO's and the investment rate on the commercial paper rate $(r)$ by decade, 1886-2002.

\begin{tabular}{|c|c|c|c|c|}
\hline \multirow[b]{3}{*}{$r_{t}$} & \multicolumn{4}{|c|}{ 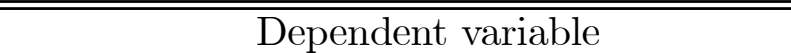 } \\
\hline & \multicolumn{2}{|c|}{ IPOs / Stock Market } & \multicolumn{2}{|c|}{$I / K$} \\
\hline & $\begin{array}{c}0.20 \\
(0.86)\end{array}$ & $\begin{array}{c}0.56 \\
(1.71)\end{array}$ & $\begin{array}{c}-0.16 \\
(-0.66)\end{array}$ & $\begin{array}{c}0.21 \\
(0.61)\end{array}$ \\
\hline$r_{t}^{2}$ & & $\begin{array}{c}-0.11 \\
(-1.48)\end{array}$ & & $\begin{array}{c}-0.11 \\
(-1.45)\end{array}$ \\
\hline constant & $\begin{array}{c}3.13 \\
(4.23)\end{array}$ & $\begin{array}{c}3.51 \\
(4.71)\end{array}$ & $\begin{array}{c}6.37 \\
(8.08)\end{array}$ & $\begin{array}{c}6.76 \\
(8.49)\end{array}$ \\
\hline$R^{2}$ & .07 & .25 & .04 & .22 \\
\hline$N$ & 12 & 12 & 12 & 12 \\
\hline
\end{tabular}

Note: t-statistics are in parentheses. 
To examine the low-frequency relationship between these measures of investment and $r$ more precisely, we again average across ten year periods.

Figure 10 shows a scatterplot of decadal averages of $r$ on IPO value, along with the fitted values from a quadratic regression. Figure 11 shows the scatterplot and linear regression line for incumbent investments. We report the details of the quadratic regressions and their linear counterparts in Table 2. For IPO investment, the linear term is positive and statistically significant at the 5 percent level, while the coefficient on the quadratic term is negative and approaching statistical significance. We interpret this as evidence for the inverted U-shape that the model predicts. With incumbent investment, we also find an inverted U-shape, but the coefficient on the linear term is much smaller and not statistically significant. A linear fit thus seems more appropriate, and this is what we show in Figure 11.

\subsection{Testing $T$ vs. the capital-output ratio}

The model's third implication is that firms with capital-intensive projects will wait longer to have an IPO than firms with projects that are less capital intensive. We test this at the sectoral level using the 1987 Standard Industry Classifications to construct the ratio of fixed assets to GDP for 49 sectors from the detailed tables made available by the Bureau of Economic Analysis (2003). To ensure an adequate number of observations to estimate mean waiting times by sector, we pool our IPO data over the period from 1987-2002. To match this timing with that chosen for the capital-output ratio, we average it over the same period.

Table 3. Regressions of waiting times to IPO on the capital-output ratio $(K / Y)$ by sector, 1987-2002.

\begin{tabular}{|c|c|c|}
\hline & \multicolumn{2}{|c|}{ Dependent variable } \\
\hline & $T$ from founding & $T$ from incorporation \\
\hline \multirow[t]{2}{*}{$K / Y$} & -0.08 & 0.72 \\
\hline & $(-0.05)$ & $(0.68)$ \\
\hline \multirow[t]{2}{*}{ constant } & 21.27 & 11.87 \\
\hline & $(7.09)$ & $(5.03)$ \\
\hline$R^{2}$ & .00 & .01 \\
\hline$N$ & 48 & 49 \\
\hline
\end{tabular}

Note: t-statistics are in parentheses.

The results, reported in Table 3, indicate that there is no statistically significant relationship between sectoral capital-output ratios and mean waiting times, whether measured by years from founding or years from incorporation. According to our model 
this can happen only if the main difference is variation in learning opportunities as expressed by $\alpha$.

\subsection{Testing $T$ vs. IPO Size}

The model's fourth implication deals with the relation between the size of an IPO and the delay in having it. If the overriding source of variation in the data is changes in pre-IPO growth opportunities, we should find a positive relation between IPO size, $v$, and IPO-ing firm age, $T$. On the other hand, variation in $I$ would produce a negative relation. We examine this using firm-level data on IPO size and our database of waiting times, measuring IPO size as the market value of a firm at the end of the year in which it enters CRSP after converting to millions of 2002 dollars using the implicit price deflator for GDP.

Table 4. Firm-level regressions of waiting times $(T)$ on real IPO size $(v)$ by decade, 1886-2002.

\begin{tabular}{|c|c|c|c|c|}
\hline & \multicolumn{4}{|c|}{ "Dependent variable } \\
\hline & $T$ from & unding & $T$ from & rporation \\
\hline$v_{t}$ & $\begin{array}{c}0.00335 \\
(10.15)\end{array}$ & & $\begin{array}{r}0.00195 \\
(8.65)\end{array}$ & \\
\hline $\log (v)$ & & $\begin{array}{c}3.44 \\
(11.42)\end{array}$ & & $\begin{array}{c}2.154 \\
(11.20)\end{array}$ \\
\hline$R^{2}$ & .52 & .53 & .47 & .48 \\
\hline$N$ & 4206 & 4206 & 6264 & 6264 \\
\hline
\end{tabular}

Pooling our IPO data from 1886 to 2002 and including yearly dummies in regressions of $T$ on $v$ and $T$ on $\log (v)$, we find the relationship to be positive and statistically significant in all cases. Table 4 shows these results, which support the view that variations in $\alpha$ dominate the relation. Therefore this test, as did the previous one, suggests that the main reason why $T$ varies over time is changes in learning opportunities as expressed by $\alpha$.

\subsection{Testing IPO Size vs. $r$}

The model's fifth main implication is that the relation between the real rate of interest and IPO size should be negative at low rates of interest, and ambiguous at higher rates. As in our tests of investment and $r$, we pool across decades using the average real rate on short-term commercial paper. We then compute the average size of firms entering CRSP in each year and average them across decades to construct the dependent variable. Our regression of IPO size on $r$ yielded 


$$
\text { IPOsize }=318.69+2.862 r \quad \mathrm{R}^{2}=.002, \mathrm{~N}=12 .
$$

No discernible relation exists between IPOsize and $r$. This is what one would expect at higher interest rates, but the model does predict that at lower levels of $r$ the relation should be negative. The likely explanation for why we do not find this is the volatility of stock prices. IPO size is measured as the firm's stock market value right after its IPO. This measure fluctuates with the stock market and introduces noise into the variable IPOsize that is not present in our measures of a firm's age.

\subsection{Summary of the empirical results}

The implications of the model are on the whole confirmed. This is especially true of those regarding the backward-bending IPO-investment schedule. The evidence is easier to reconcile with the model if one assumes that learning opportunities, as summarized by the parameter $\alpha$, have varied over time and over sectors.

\section{Other theories and evidence}

Our focus has been on the individual firm's decision, and not the aggregate equilibrium aspects surrounding IPOs. Had we analyzed these, we would have needed to mention economies of scale in IPO activity and start-up activity (due, e.g., to concentration of focus by venture capitalists), and to discuss the models of Diamond (1982) and Veldcamp (2003) that could perhaps explain some IPO waves.

We have assumed that, at IPO, the public pays for the firm exactly what it is worth. In a more expansive paper one could entertain hypotheses involving waves of irrational exuberance. Along the lines of Shleifer and Vishny's (2003) paper on mergers, one could argue that perhaps IPO-ing firms wait in the wings in order to take advantage of such exuberance. If so, the beneficiaries are neither the IPO-ing firms nor the participating venture capitalists themselves: Data from Ritter (2002, 2003) show that (while being times of high IPO volume) high- $Q$ periods are, in fact, times of more severe underpricing of firms going public. In other words, models in which a naive shareholder buys overpriced firms will not explain the time-series correlation between the volume of IPOs and Tobin's $Q$. Perhaps it is only investment bankers that benefit from such exuberance.

Other evidence shows that increasing funds for investment is indeed one of the motives behinds an IPO. Jain and Kini (1994, Table 2), for example, find that by the fourth year after its IPO, the firm will experience a rise in sales of $80 \%$ compared to its industry counterparts, and $143 \%$ compared to its own sales in the year just before the IPO (see also Choe, Masulis and Nanda 1993, Lowry 2002, and Moskowitz and Vissing-Jorgensen 2002). We find that the 1955-2002 correlation between funds that firms take in at IPO and their real investment is 0.33 and highly significant. 
Aside from taking more capital in, an additional gain from an IPO may be a rise in the firm's efficiency. This motive is implicit in Greenwood and Jovanovic (1990). Jain and Kini's evidence that sales surge may be in part because of a rise in efficiency. It has been said that being public imposes greater transparency and more regulation on the firm, but it also delivers a lot more analyst coverage and greater discipline because of takeover pressure. This, presumably, is largely what we mean by there being advantages to financial development and to the existence of well-functioning stock markets. Greenwood and Jovanovic (1990) focus on the information-generating role of financial markets, and their story fits the fact that a private company gets no analyst coverage until it is about to have its IPO.

Our assumption that the firm's investment occurs at the time of IPO brings us closer to the literature on liquidity constraints. When an entrepreneur has a high return activity than he cannot fund in the capital market, he has a greater incentive to save because those savings can fund an investment that is more profitable than the average market investment. Buera (2003) analyzes optimal saving behavior by liquidity-constrained entrepreneurs.

\section{Conclusion}

We have presented and tested a neoclassical model with liquidity constraints. In this model delay to IPO occurs because the firm is trying to improve its idea to the point where it becomes optimal to incur the fixed cost of an IPO. From different premises we have derived a result that is also in Chetty (2003) and Jovanovic and Rousseau (2001), who show that when waiting leads to better information, the incentive to delay can imply a backward-bending investment schedule as a function of the rate of interest.

The investment schedule bends back because an irreversible investment is needed for production, and because waiting makes that investment more productive. As Chetty (2003) makes clear, the tension between these two forces can arise generally, and not just in the context of IPOs.

At the same time, the result that IPO investment is rising in the real interest rate (when that rate is low) is really a result about the composition of capital. Total investment (including information investment) may still be monotone-decreasing in the interest rate. Firms postpone physical investment, but they gather information, and this is human capital. Before its IPO, the value of the firm is monotone-decreasing in the interest rate, and that value - i.e., the value of the physical and human capital combined - is being maximized by the firm's policy. Thus when physical investment rises with the interest rate, this simply means that the firm's human capital investment is falling, and perhaps so does total capital properly measured. Therefore Japan may be in better shape than it seems today because those very individuals that are not investing may be accumulating a different kind of capital that is not measured as 
such. On the other hand, the model does not explain why established corporations do not respond more elastically to reductions in interest rates.

\section{References}

[1] Berry, T. S. (1988), "Production and population since 1789: revised GNP series in constant dollars", Bostwick Paper No. 6 (The Bostwick Press, Richmond, VA).

[2] Bradstreet Co. (1885-1925, various issues), Bradstreet's (Bradstreet Co., New York).

[3] Buera, Francisco. "A Dynamic Model of Entrepreneurship with Borrowing Constraints." Manuscript, University of Chicago, November 2003.

[4] Chetty, Raj. "Interest Rates and Backward-Bending Investment." Manuscript, UC Berkeley, 2003, and forthcoming NBER Working Paper.

[5] Clementi Gian Luca. "IPOs and The Growth of Firms." Manuscript, Stern School of Business, New York University, April 2002.

[6] Choe, Hyuk, Ronald Masulis and Vikram Nanda. "Common Stock Offerings Across the Business Cycle." Journal of Empirical Finance 1 (1993): 3-31.

[7] The Commercial and Financial Chronicle (1885-1925, various issues).

[8] Diamond, Peter. "Aggregate Demand Management in Search Equilibrium." Journal of Political Economy 90, no. 5, (October 1982): 881-94.

[9] Dun and Bradstreet, Inc. (2003), D\&B Million Dollar Directory (Dun and Bradstreet Inc., Bethlehem, PA).

[10] Federal Reserve Bank of St. Louis (2003), FRED Database (Federal Reserve Bank of St. Louis, St. Louis, MO).

[11] Greenwood, Jeremy and Boyan Jovanovic. "Financial Development, Growth, and the Distribution of Income." Journal of Political Economy 98, no. 5 (October 1990): 1076-1107.

[12] Hayashi, Fumio. "Tobin's Marginal q and Average q: A Neoclassical Interpretation." Econometrica 50, No. 1. (Jan., 1982), pp. 213-224.

[13] Homer, Sidney, and Richard Sylla (1991), A History of Interest Rates, 3rd Edition (Rutgers University Press, New Brunswick, NJ).

[14] Jain, Bharat A., and Omesh Kini. "The post-issue operating performance of IPO firms." Journal of Finance 49 (December 1994): 1699-1726. 
[15] Jovanovic, Boyan, and Peter L. Rousseau. "Why Wait? A Century of Life Before IPO." American Economic Review (Papers and Proceedings) 91, no. 2 (May 2001): 336-341.

[16] Kelley, E. M. (1954), The Business Founding Date Directory (Morgan and Morgan, Scarsdale, NY).

[17] Kuznets, Simon S. Capital in the American Economy: Its Formation and Financing. Princeton University Press, Princeton, NJ, 1961a.

[18] Kuznets, Simon S. "Annual estimates, 1869-1955." Manuscript, Johns Hopkins University, Baltimore, MD, 1961b.

[19] Lee, Inmoo, Scott Lockhead, Jay Ritter, and Quanshui Zhao. "The Costs of Raising Capital." Journal of Financial Research 19, no.1 (Spring 1996): 59-74.

[20] Lowry, Michelle. "Why Does IPO Volume Fluctuate So Much?" Journal of Financial Economics (2002):

[21] Moody's Investors Service (1920, 1929, 1931, 1941, 1951, 1956, 1961), Moody's Industrial Manual. (Moody's Investors Service, New York).

[22] Moskowitz, Tobias J., and Annette Vissing-Jorgensen. "The Returns to Entrepreneurial Investment: A Private Equity Premium Puzzle?" American Economic Review 92, no. 4 (September 2002): 745 - 778.

[23] The New York Times Co. (1897-1928, various issues), The New York Times (The New York Times Co., New York).

[24] The New York Times Co. (1913-1925, various issues), The Annalist: A Magazine of Finance, Commerce, and Economics (The New York Times Co., New York).

[25] Pastor, Lubos, and Pietro Veronesi. "Stock Prices and IPO Waves." NBER working paper w9858, July 2003.

[26] Ritter, Jay R. "Some Factoids About the 2002 IPO Market." Manuscript, University of Florida, January 2003.

[27] Ritter, Jay. "Long-run Returns on IPOs from 1970-2002." Manuscript, University of Florida, 2003.

[28] Shleifer, Andrei. "Implementation Cycles." Journal of Political Economy 94, no. 6 (December 1986): 1163-90.

[29] Shleifer A, Vishny RW "Stock Market Driven Acquisitions." Journal of Financial Economics 70, no. 3 (December 2003): 295-311. 
[30] Standard and Poor's Corporation (1981, 1988, 2000, 2002), Stock Market Encyclopedia (Standard and Poor's Corporation, New York).

[31] Standard and Poor's Corporation (various years), Stock Reports (Standard and Poor's Corporation, New York).

[32] United States Bureau of Economic Analysis, Survey of Current Business. Government Printing Office, Washington, DC, 2003.

[33] University of Chicago Center for Research on Securities Prices. CRSP Database. University of Chicago Center for Research on Securities Prices, Chicago, IL, 2002.

[34] Veldcamp, Laura. "Media Frenzies in Markets for Financial Innovation." Manuscript, NYU, June 2003. 